of unemployment when trying to obtain a registrar post. ${ }^{78}$

That these difficulties are due, at least in part, to discrimination was shown by Esmail and Everington in 1993.9 They sent matched pairs of curriculum vitae-one bearing an English name and one an Asian name-in response to 23 advertisements for senior house officer posts. The applicants with English names were more likely to be shortlisted.

In the late 1980s and early 1990s there was a flurry of initiatives to combat discrimination in medicine. In 1989 the Universities Central Council on Admissions started monitoring the ethnic status of applicants. A joint task force was also set up by the Department of Health and the King Edward's Hospital Fund for London to report on how to achieve racial equality in selecting hospital doctors. It produced guidance for all those involved in selection procedures in $1990 .^{10}$ The NHS Executive issued specific guidelines on equal opportunities in recruitment and selection procedures in 1991." ${ }^{11}$. But the papers published in this week's $B M \mathcal{~ , ~ t h e ~ r e c e n t ~ r e p o r t ~ f r o m ~ M a n c h e s t e r , ~ a n d ~ t h e ~ f a c t ~}$ that Esmail and Everington were still able to show overt discrimination in 1993 indicate that these measures were not enough. This is partly because the guidelines are voluntary but also because they have not been linked to any effective monitoring of their impact.

If we wish to eradicate a systematic problem we need a systematic approach. The Commission for Racial Equality has produced guidance to help employers to be more rigorous in their attempts at achieving racial equality. Their booklet, Racial Equality Means Business: A Standard for Racial Equality for Employers gives a step by step guide on how to develop strategies and monitoring schemes. It also goes further by showing how to monitor the impact of these strategies in areas of policy and planning; selecting, developing, and retaining staff; communicating the corporate image, corporate citizenship, and auditing for racial equality. ${ }^{12}$ There is a strong case for the commission's standard to be made mandatory across the whole NHS and in every medical school. This should be centrally coordinated so data across the NHS could be made available. It could produce information on applications, shortlisting, and success rates at interview for all groups who are discriminated against and tie these to a process of audit and development. It could identify where change is necessary nationally and locally.

Audit can yield dividends. McManus et al have used the ethnic monitoring data from university admission forms to identify areas where change could make medical school selection fairer. Similarly, the working party set up after the examination failures in Manchester has called for more structured marking in clinical examinations to cut down the opportunities for discrimination. ${ }^{6}$

The discrimination which is evident in medicine means that good students are denied places at medical school and good doctors denied their chosen careers. If we do not choose the best person for the job because of his or her ethnic background then the practice of medicine suffers from the wasted potential as much as the individual. The image of medicine in the eyes of patients is also damaged. From April this year the NHS is to undertake mandatory ethnic monitoring of all patients to increase equity of care, but we are unlikely to produce an equitable NHS for patients if we do not have the will to produce it for doctors.

$B M 7$,

KWAME J MCKENZIE Visiting associate editor

London WC1H

1 McManus IC Richards P, Winder BC, Proston KA, Styles V. Medical school applicants from minority ethnic groups: identifying if and when they are disadvantaged. $B M 71995 ; 310: 496-500$.

2 Esmail A, Nelson P, Primarolo D, Toma T. Acceptance into medical school and racial discrimination. $B M \mathcal{F}$ 1995;310:501-2.

3 McManus IC, Richards P. Audit of admissions to medical school. 1. Acceptances and rejects. BMF 1984;289:1201-4.

4 McManus IC, Richards P, Maitlis SL. Prospective study of the disadvantage of people from ethnic minority groups applying to medical school in the United Kingdom. BMF 1989;298:723-6.

5 Commission for Racial Equality. Report of a formal investigation into St George's Hospital Medical School. London: CRE, 1988.

6 Dillner L. Manchester tackles failure rate of Asian students. $B M F$ 1995;310:209.

7 Commission for Racial Equality. Overseas Doctors: A Research Study. London: CRE, 1987.

8 McKeigue PM, Richards JDM, Richards P. Effects of discrimination by sex and race on the early areers of British medical graduates during 1981-7. BMF 1990;301:961-4.

9 Essmail A, Everington S. Racial discrimination against doctors from ethnic minorities. $B M \mathfrak{I}$ 1993;306:691-2.

\title{
Analgesic headache
}

\section{A common, treatable condition that deserves more attention}

"Do no harm" is the first commandment for clinicians, but effective drug treatment cannot be given without exposing patients to the risk of side effects. One side effect quite often observed in the treatment of headache is rarely seen in other conditions: the treatment may aggravate the symptom for which it has been given. Ergotamine, narcotics, and even mild analgesics may all aggravate tension headache and migraine when taken daily. ${ }^{2}$

Ergotamine has a relatively short half life in plasma but a longlasting effect on arteries, ${ }^{3}$ and its frequent use may induce almost permanent vasoconstriction. ${ }^{4}$ Headache induced by ergotamine is of two types. ${ }^{5}$ One type is associated with daily use of ergotamine and is present almost constantly but fluctuates in intensity and characteristics: sometimes it fulfils the criteria for migraine, but at other times it does not. The second type is associated with sudden discontinuation of daily ergotamine, and this may cause a severe and protracted attack of migraine. Vasodilatory counteracting mechanisms that develop during chronic use of ergotamine are left unopposed when the drug is withdrawn, and this may explain the ergotamine withdrawal headache. The only effective treatment is to start ergotamine again, so the patient is caught in a vicious circle of use and abstinence from the drug. Admission to hospital may be needed to break this pattern.

Sumatriptan, the specific remedy against migraine that was introduced recently, may theoretically cause the same problems. Treatment with sumatriptan has been shown to ameliorate ergotamine withdrawal headache. ${ }^{6}$ In most migraine centres a few patients have been found to be misusing sumatriptan, ${ }^{7}$ but the drug seems only rarely to aggravate headache or migraine in people who are not already misusing another drug. The pharmacological differences between ergotamine and sumatriptan probably explain why sumatriptan rarely causes drug induced headache and why stopping overconsumption is relatively easy.

In Denmark narcotics have been widely used for migraine. As a result, each year, an estimated 13 people per million have become dependent on these drugs after taking them for migraine. ${ }^{8}$ Recently the problem has been brought under control by education of the profession. Centrally acting 
analgesics should not be used to treat migraine or tension headaches.

Large daily doses of mild analgesics may also aggravate headaches. Experience in Germany, Switzerland, Britain, and the United States has shown that mixed analgesic compounds containing aspirin or paracetamol in combination with a barbiturate, a benzodiazepine, or a narcotic such as dextropropoxyphene are probably the strongest inducers of chronic analgesic headache. ${ }^{6}$ Whether pure aspirin or paracetamol may do the same is less certain.

The clinical importance of analgesic headache is shown by the number of studies reporting substantial improvement in the frequency or severity of headaches after daily analgesics are stopped. ${ }^{1346}$ Nevertheless, the mechanisms of this type of headache remain unclear. Analgesics induce headache only in people who suffer headaches-not when given for other diseases such as rheumatoid arthritis. ${ }^{16}$ Either the pain pathways in patients with headaches are specially prone to sensitisation by daily analgesics or the analgesic headache must be a state of psychological dependence. Analgesics on a fixed schedule are more effective in treating chronic pain than analgesics given on demand; but virtually all patients with headaches who overconsume analgesics take their drugs on demand-constantly focusing their attention on the headache and the drug. Increased attention is known to increase sensitivity to painful stimuli and so might be a relevant mechanism. ${ }^{9}$ A double blind, placebo controlled withdrawal experiment is required, but unfortunately such a study has not been done.

Despite the deficiencies in our knowledge of the mechanisms of analgesic headache several recommendations for its prevention can be made with confidence. ${ }^{6}$ Patients with headaches should never take analgesics every day: the maximum should be set at 15 days a month. Ergotamine should probably not be taken more than 10 times a month, and the same (or perhaps a slightly higher frequency) applies to sumatriptan. Narcotics should not be used at all. Compound analgesics should be avoided as far as possible. If these simple precautions were all followed new cases of analgesic headache should become rare.

Finally, what can be offered to the many patients who already suffer from analgesic headache? A careful explanation of the mechanisms of the headache and its prevention, frequent consultations, and psychological support should make it possible for the drug to be withdrawn in most cases. Once withdrawal has been achieved prognosis is favourablethe relapse rate, even in cases of severe overuse of ergotamine, is only around $30 \% .{ }^{10}$ This unpleasant and often disabling condition deserves more attention.

JES OLESEN

University of Copenhagen,

Professor of neurology

Department of Neurology,

Glostrup Hospital,

Copenhagen,

Denmark

1 Diener HC, Wilkinson M. Drug induced headache. Berlin, New York: Springer Verlag, 1988:1-173.

2 Olesen J, Tfelt-Hansen P, Welch KMA. The headaches. New York: Raven Press, 1993:1-894.

3 Tfelt-Hansen P. The effect of ergotamine on the arterial system in man. Acta Pharmacol Toxicol 1986;59(suppl 3):1-30.

4 Dige-Petersen H, Lassen NA, Noer I, Tønnesen KH, Olesen J. Subclinical ergotism. Lancet 1977;ii:65-6.

5 Headache Classification Committee of the International Headache Society. Classification and diagnostic criteria for headache disorders, cranial neuralgias and facial pain. Cephalalgia 1988;8(suppl 7):1-96.

6 Diener HC, Tfelt-Hansen P. Headache associated with chronic use of substances. In: Olesen J, Tfelt-Hansen P, Welch KMA, eds. The headaches. New York: Raven Press, 1993:721-7.

7 Osborne MJ, Austin RCT, Dawson KJ, Lange L. Is there a problem with long term use of sumatriptan in acute migraine? $B M \mathcal{F}$ 1994;308:113.

8 Langemark M, Olesen J. Drug abuse in migraine patients. Pain 1984;19:81-6.

9 Bushnell MC, Duncan GH, Dubner R, He LF. Activity of trigeminothalamic neurons in medullary dorsal horn of awake monkeys trained in a thermal discrimination task. $\mathcal{f}$ Neurophysiol 1984;52:170-87.

10 Tfelt-Hansen P, Krabbe AA. Ergotamine abuse. Do patients benefit from withdrawal? Cephalalgia $1981 ; 1: 29-32$.

\title{
Better ways of assessing health needs in primary care
}

\author{
Requires adapting conventional methods
}

Commissioning authorities increasingly attempt to base their purchasing decisions on systematic, epidemiologically informed assessment of the health needs of their local populations. General practitioners as purchasers usually rely on their own judgment. No one knows which method works better, but a combined approach may capture some of the advantages of both.

One of the more widely welcomed aspects of the NHS reforms was the requirement that health authorities' decisions on how to use NHS resources should in future be based on a systematic assessment of each local population's needs for health care. This is meant to take account of local demography, the epidemiology of health problems, evidence on the effectiveness of treatments, and the preferences of local people. ${ }^{1}$ Needs assessment has become an important task for public health doctors and others working in commissioning authorities. This more rational and scientific method is put forward as an improvement over the former approach to allocating health funding, caricatured as "same as last year, plus or minus five per cent for pressure groups." 2

The most obvious way in which general practitioners can shape decisions on the pattern of purchasing for hospital and community health services is by becoming fundholders. Nonfundholding general practitioners may influence commission- ing decisions made by health authorities in various ways, ${ }^{3}$ but not much has been done to develop a method of systematically assessing health care needs in primary care. General practitioners may therefore find themselves limited to their unaided judgment of which services would most benefit the health of local people.

An approach that explicitly combines epidemiological analysis with the personal knowledge of primary care practitioners has several advantages. A strength of the epidemiological approach is its ability to look beyond patients who already demand health care to those don't demand it but need it. Homeless people and those with chronic severe mental illness may be among these invisible potential patients. The main advantage of the primary care perspective is the personal knowledge that primary health care teams derive from extended day to day contact with their patients. This informed opinion can be enhanced by the systematic analysis of data that already exist in the practice or are specially collectedfor example, by rapid appraisal survey. ${ }^{4}$ General practitioners' direct experience as referral agents also enables them to assess the quality of service delivered by local providers. ${ }^{5}$

What has been described as "living epidemiology" might start with the basic demography of the practice population, extracted from the age-sex register. ${ }^{6}$ Information on present- 